\title{
Review and Case Studies of Non-Traditional Severe Local Windstorms
}

\author{
TIMOTHY A. COLEMAN and KEVIN R. KNUPP \\ The University of Alabama in Huntsville, Huntsville, Alabama
}

(Manuscript received 12 February 2016; review completed 4 August 2016)

\begin{abstract}
Several phenomena not traditionally thought of as severe local storms may produce high winds and subsequent wind damage. These include wake lows, solitary waves, and steep cold fronts. In this paper, the basic dynamics of these phenomena are reviewed, including how they produce strong winds. Impedance relations are shown to provide a good indicator of the potential winds from these pressure perturbation events. A case study of each phenomenon producing significant winds or wind damage is presented, including operational clues that the event is imminent or in progress.
\end{abstract}

\section{Introduction}

Most meteorologists think of severe local windstorms as tornadoes, "straight-line winds" from a quasi-linear convective system (QLCS), or perhaps microbursts. However, during the past few years, more attention has been given to wake lows and the wind damage they produce; the distinction between wake lows and gravity waves has occasionally been blurred. In addition, high-amplitude atmospheric solitary waves and very steep cold fronts may also produce wind damage. These non-traditional events may be more difficult to identify and detect than tornadoes or QLCSs because they less commonly produce wind damage - in some cases resulting in the damage occurring prior to hazard warnings being issued.

In this paper, we discuss the basic dynamics and tell-tale signs of these non-traditional, wind damageproducing atmospheric events, and then analyze at least one case study of each type. We first consider wake lows, local areas of low pressure generated at the back edge of the stratiform rain region of a mesoscale convective system (MCS), including many QLCSs (e.g., Fujita 1955; Gaffin 1999; Johnson 2001; Handel and Santos 2005; Coleman and Knupp 2011a, hereinafter CK11). The large and transient pressure gradients associated with a wake low can produce widespread wind damage, and become a significant weather event across multiple National Weather Service (NWS) county warning areas.
Second, we examine solitary waves, a special type of atmospheric gravity wave that maintains balance over a long time period (Christie et al. 1978; Doviak and $\mathrm{Ge}$ 1984). When these have large pressure perturbations and move slowly, they may produce significant winds. Specific aspects of a solitary wave examined by Ruppert and Bosart (2014) will be highlighted over a relatively small area to detail the production of damaging winds.

The third phenomenon is a very steep cold front associated with a very rapid pressure rise. When the temperature gradient, and therefore the surface pressure gradient, becomes very large, significant winds can develop in the cross-frontal direction. We examine a cold front that produced widespread wind damage on 29-30 January 2008.

For all phenomena, we also include a summary of operational clues that indicate that the event is imminent or occurring.

\section{Data and methods}

Three primary datasets used in the case study analyses are observed surface pressure, temperature, and wind (time series at a point and/or mesoscale analysis). Sounding data are used to show regions of stability and potential warming and cooling due to sudden vertical motion. Radar data (both reflectivity and velocity) are used to show the precipitation and kinematics of the systems. Parcel trajectories calcu- 
lated using time-to-space conversion of radar velocity data made the assumption that the wake low or solitary wave being examined was two-dimensional and steady-state. A field of wind speed, convergence, and vertical motion was calculated, and parcels flowed through this field, producing trajectories. For more information on this trajectory analysis, see Coleman and Knupp (2011b). Also, to determine the theoretical surface pressure change attributable to a parcel's ascent or descent, sounding data were used; potential temperature and the Brunt-Väisälä frequency $(N)$ were determined at given levels, then each level was raised or lowered adiabatically, according to the trajectory information. Using Eq. (1) (see section 3), the surface pressure perturbation was determined for each sounding layer and multiplied by the height between that layer and the next - providing a full integration for all layers between the two sounding levels. Data from the University of Alabama in Huntsville (UAH) Mobile Integrated Profiling System (MIPS), microwave profiling radiometer (MPR) were used to illustrate a timeheight section of potential temperature as a steep cold front passed by a given location, and North American Mesoscale Model (NAM) data were used to construct a cross section of potential temperature through the cold front.

\section{Reviews and case studies}

a. Wake lows

A wake low is a mesoscale area of surface low pressure at the rear of an MCS. The scientific consensus is wake lows are associated with subsidence at the rear of an MCS (e.g., CK11). According to Johnson and Hamilton (1988), the subsidence is associated with the rear inflow jet (RIJ) in the MCS (Fig. 1). Many studies have shown wake lows are most intense when the horizontal component of the RIJ is essentially "blocked" (decelerated to near zero) by the stratiform precipitation area; the relatively dry air in the RIJ is cooled rapidly when it encounters the precipitation, initially causing negative buoyancy and appreciable subsidence within the RIJ, and convergence aloft (e.g., Stumpf et al. 1991; Johnson and Bartels 1992). Microphysical cooling processes (e.g., Gallus 1996) in the descending air, including melting and evaporation, are more than offset by the adiabatic warming associated with descent. Sometimes a parcel will gain enough downward momentum that it will continue to descend - even upon interaction with a stable layer near the surface and subsequent realization of positive

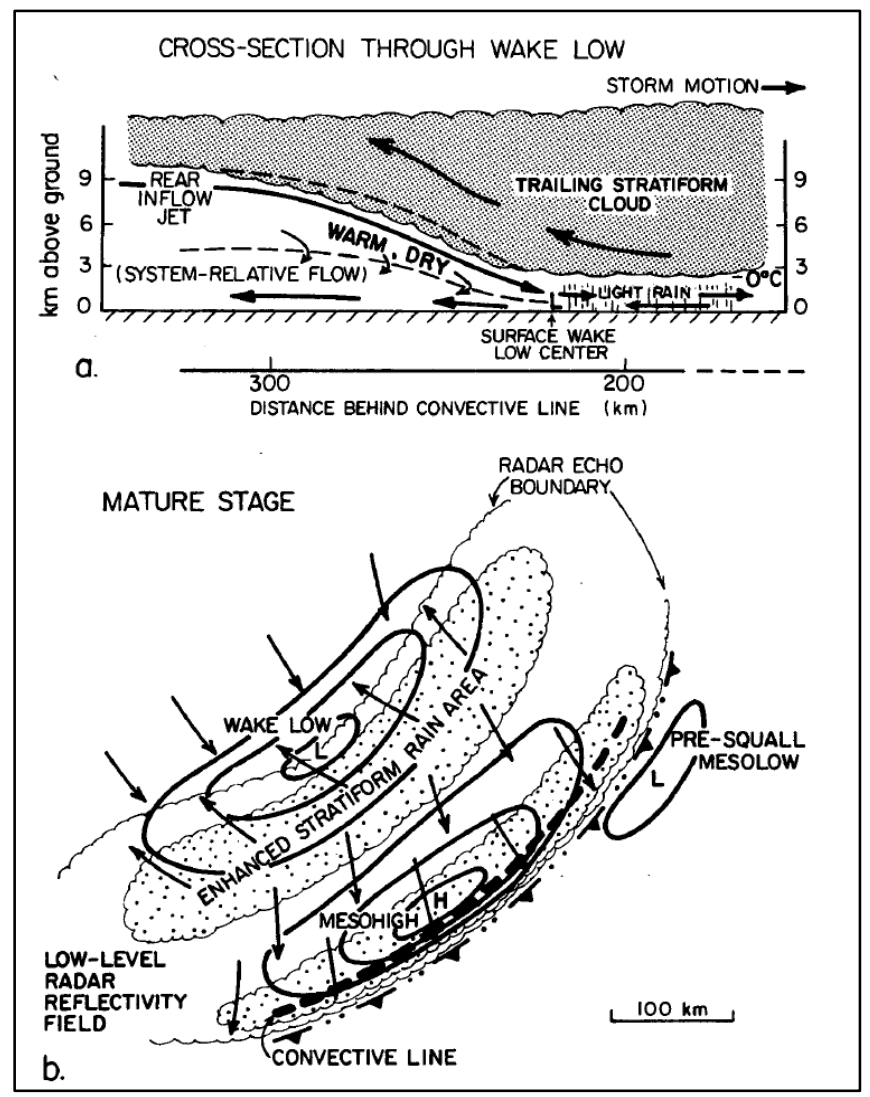

Figure 1. Schematic of a wake low (top shows cross section, bottom shows plan view) adapted from Johnson and Hamilton (1988). Click image for an external version; this applies to all figures hereafter.

buoyancy. This is called an "overshooting" bottom (e.g., Johnson and Hamilton 1988; Smull and Jorgensen 1990; Smull et al. 1991; Gallus and Johnson 1995), and may produce large magnitude warm perturbations at low-levels in the atmosphere.

The warm perturbation aloft hydrostatically produces negative pressure perturbations at the surface. Pressure drops in a wake low are sometimes directly associated with the downward depression of a surfacebased cold pool (e.g., Stumpf et al. 1991; Johnson 2001). Downward motion in stable air produces a larger warm perturbation and a more intense low pressure area at the surface (e.g., Bosart and Seimon 1988; Coleman 2008). Utilizing the hydrostatic equation and results from Lighthill (1978), Coleman (2008) showed the following for pressure perturbations associated with vertical displacements of air:

$$
p^{\prime}=\int_{z}^{\infty} N^{2} \rho_{0} \delta z d z
$$


where $p^{\prime}$ is the pressure perturbation at height $z, N$ is the Brunt-Väisälä frequency, $\rho_{0}$ is the mean density (a function of $z$ ), and $\delta z$ is the net vertical displacement (at each height $z$ ). This indicates for a given vertical displacement $\delta z$, the greatest $p^{\prime}$ at the surface occurs when the displacement occurs in stable air (large $N^{2}$ ) and/or at low levels (large $\rho_{0}$ ). The process of wake low formation is examined through numerical simulation by Zhang and Gao (1989).

This stable layer near the surface, typical during intense wake lows, may explain why wake lows are often misidentified as ducted gravity waves, which also require a low-level stable layer. However, the physical processes generating the two are different. The wake low is simply caused by subsidence and warming above a point on the surface, with no oscillations necessary. In contrast, ducted gravity waves are produced by a complex process wherein internal, oscillating gravity waves become ducted by a stable layer adjacent to the surface, then reflect off the ground and the top of the stable layer to produce resonance for waves with vertical wavelength equal to four times the depth of the stable layer (e.g., Eom 1975; Uccellini 1975; Lindzen and Tung 1976; Coleman and Knupp 2008).

Horizontal wind perturbations attributable to transient, highly ageostrophic pressure disturbances on the mesoscale are most closely given by impedance relations (e.g., Gossard and Hooke 1975; Coleman and Knupp 2010). The wind perturbation is proportional to the pressure perturbation, and inversely proportional to the intrinsic speed of the disturbance. Note that impedance relationships must be used carefully and may contain errors (especially when only one station's values are used). Not all pressure disturbances are purely two-dimensional, and one must separate out the pressure perturbation owing to the disturbance from synoptic-scale pressure tendencies. Generally, the winds in a wake low increase gradually as the pressure falls, with the maximum wind occurring at the time of minimum pressure - consistent with the impedance relations.

The subsidence warming producing wake lows often dries the air significantly and causes an abrupt end to the stratiform precipitation in the MCS. This abrupt end to the rainfall may appear as a large gradient in radar reflectivity near the back edge of the MCS (e.g., Haertel and Johnson 2000). These gradients are not always associated with a wake low, but are a signal indicating the possibility of a wake low, and should be further examined.
The significant winds generated by wake lows are very efficient at downing trees, because the wind typically is from an easterly direction, whereas most strong winds (from both severe local storms and frontal passages) come from a westerly direction. This may be the result of several factors. One of those is that many weaker trees affected by westerly winds have been already blown down in the more frequent westerly windstorms. Also, some trees may be protected from westerly winds by adjacent trees, but not from easterly winds (e.g., Knudson 2012). However, in some trees more growth occurs on the leeward side than on the windward side (relative to normal wind conditions, which are typically westerly in the eastern United States). This asymmetrical growth may cause some tree trunks to become elliptical and have fewer growth rings on the windward (west) side (Chaney 2001). Trees literally may acclimate themselves to climatological winds (westerly), and storm winds from the west "streamline" the trees such that the drag for winds from that direction is less than it would be for winds from the east (Mitchell 2013). Klimanek et al. (2008) pointed out that "irregular winds with frequent changes in velocity and/or direction over short distances are accepted as the most dangerous for forest stands." This may apply to the rare, strong, easterly winds resulting from wake lows.

\section{1) THE WAKE LOW OF 13 APRIL 2009}

An intense wake low on the morning of 13 April 2009 was a significant weather event covering a very large area, and even caused a fatality in Georgia (NCEI 2009). Wind damage and gusts above $20 \mathrm{~m} \mathrm{~s}^{-1}$ $(40 \mathrm{kt})$ were reported in dozens of counties in Alabama and Georgia. Pressure falls of $4 \mathrm{hPa} \mathrm{hr}{ }^{-1}$ occurred at numerous stations. The highest recorded wind gust of $26 \mathrm{~m} \mathrm{~s}^{-1}(52 \mathrm{kt})$ occurred at an unofficial elevated site in downtown Birmingham, just south of the most intense damage swath (Fig. 2), with another $25 \mathrm{~m} \mathrm{~s}^{-1}$ (50 kt) unofficial gust observed in Tuscaloosa County. A 1-min trace of pressure at Clay, Alabama, just northeast of Birmingham, is shown in Fig. 3. [Much of the analysis in this section is taken from CK11.]

In addition, the wake low was propagating toward the southeast (from $310^{\circ}$ ). Because the perturbation winds $\left(u^{\prime}\right)$ in a wake low are always in the opposite direction of wake low propagation, perturbation winds in this case were from the southeast. Surface observations showed that ambient low-level winds $(U)$ were also out of the southeast. The resulting total wind $(u)$ 


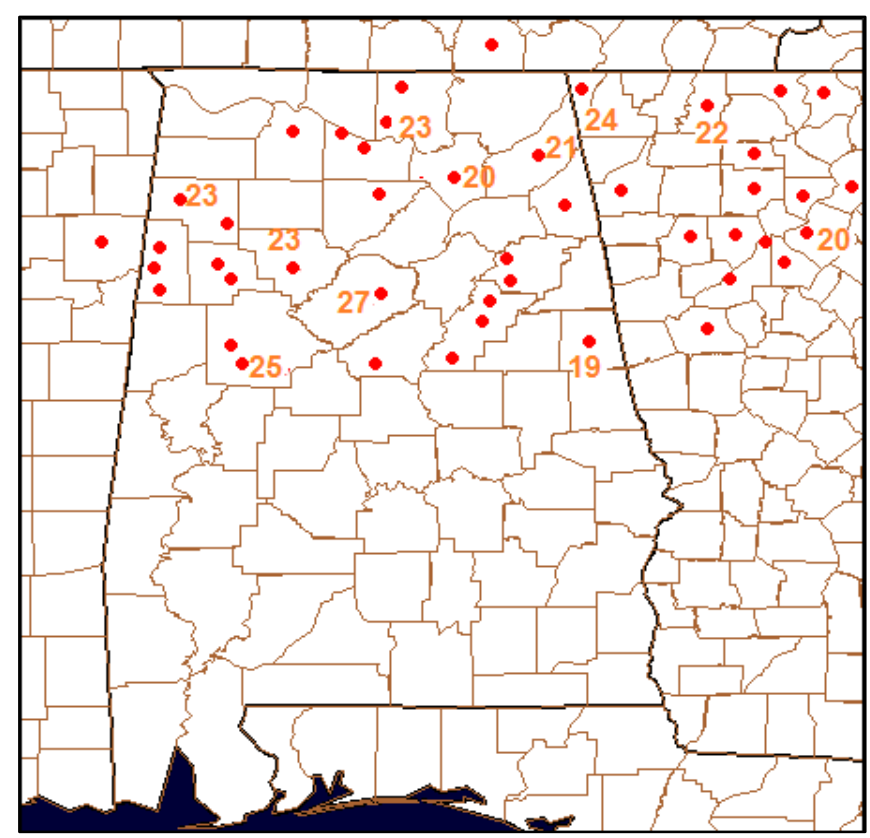

Figure 2. Locations of wind damage (dots) and measured wind gusts $\left(\mathrm{m} \mathrm{s}^{-1}\right)$ on 13 April 2009.

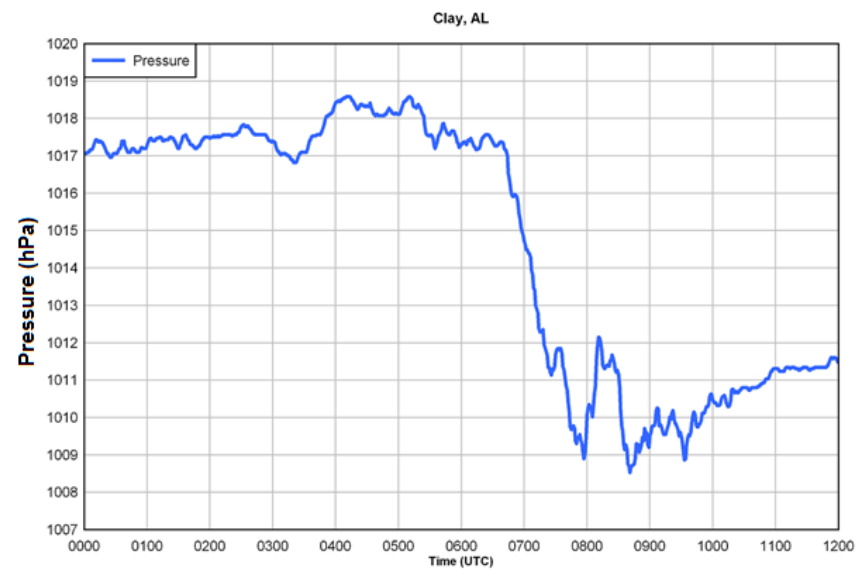

Figure 3. Plot of pressure versus time (1-min resolution) at Clay, AL, on 13 April 2009.

in a pressure disturbance equals the vector sum of the background wind and the perturbation wind $(u=U+$ $\left.u^{\prime}\right)$. Therefore, the ambient southeasterly winds caused even higher net winds (e.g., Coleman and Knupp 2009).

PPI radar reflectivity observations from 13 April 2009 (Fig. 4) showed an asymmetric MCS with a long, fairly sharp gradient in radar reflectivity at the back edge of the MCS. As explained in CK11, the "cone of silence" (COS) in radar cross sections was eliminated by assuming that the wake low was a two-dimensional, steady-state system over a short period of time. In this analysis, a time-to-space conversion was performed

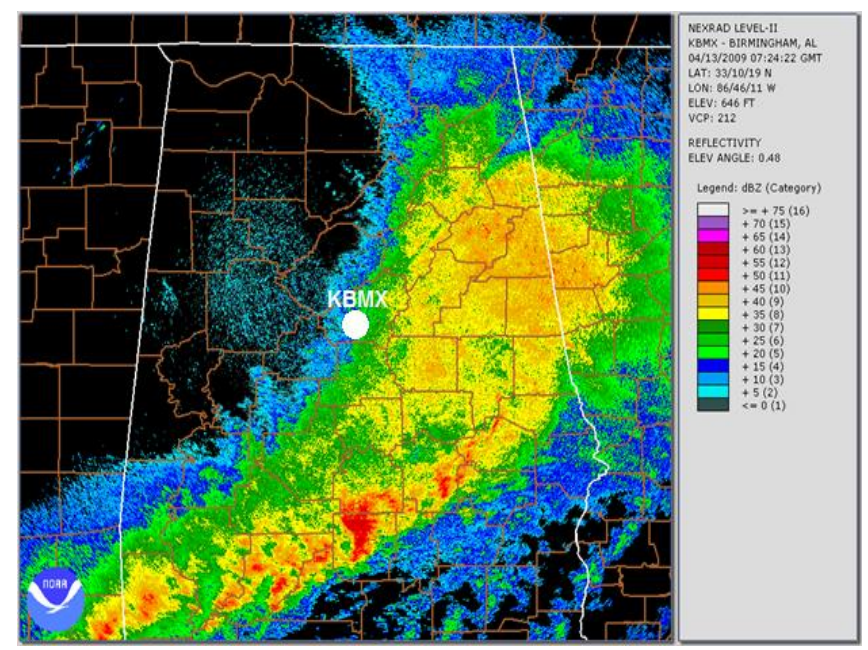

Figure 4. Radar reflectivity at $0.5^{\circ}$ elevation from the Birmingham (KBMX) WSR-88D valid 0724 UTC 13 April 2009. Click image for an animation from 0200 to 0857 UTC 13 April 2009.

using data from an earlier volume scan to show features obscured by the COS at the time of the main volume scan time. These radar cross sections show that the sharp cutoff in reflectivity extended almost $3 \mathrm{~km}$ vertically (Fig. 5a), underneath anvil precipitation. The horizontal gradient in reflectivity likely indicated significant subsidence and evaporation of precipitation. This was likely associated with the descending rear-inflow (Fig. 5b) that began to decelerate at a range of $-25 \mathrm{~km}$ from the radar. Winds in the RIJ (the 2 to $6 \mathrm{~km}$ AGL layer) decelerated from a layer average of $14 \mathrm{~m} \mathrm{~s}^{-1}(28 \mathrm{kt})$ to a layer average of $11 \mathrm{~m} \mathrm{~s}^{-1}$ (22 $\mathrm{kt}$ ) in a short distance near a range of $-25 \mathrm{~km}$ (see Fig. $5 b)$, and the RIJ horizontal winds completely "blocked" (decelerated to zero) near the $+25 \mathrm{~km}$ range. Note that low-level southeasterly winds began near the location of the final blocking (near $+25 \mathrm{~km}$ range), but accelerated to a maximum near the area where the initial large deceleration in the RIJ occurred. This large deceleration caused the (i) subsidence and erosion of the precipitation around the $-25 \mathrm{~km}$ range and (ii) maximum surface winds there.

Approximate two-dimensional parcel trajectories within the 310 to 130 degree azimuth plane were calculated for parcels with various starting positions at 0637 UTC 13 April 2009 (Fig. 6). These parcels began at the time of the radar cross sections in Fig. 5; then, assuming a form-preserving wake low moving at a constant speed, the parcels were allowed to move through the two-dimensional cross section of air flow (see section 2). Note the significant downward displacement of parcels in the RIJ, some larger than $2 \mathrm{~km}$ 


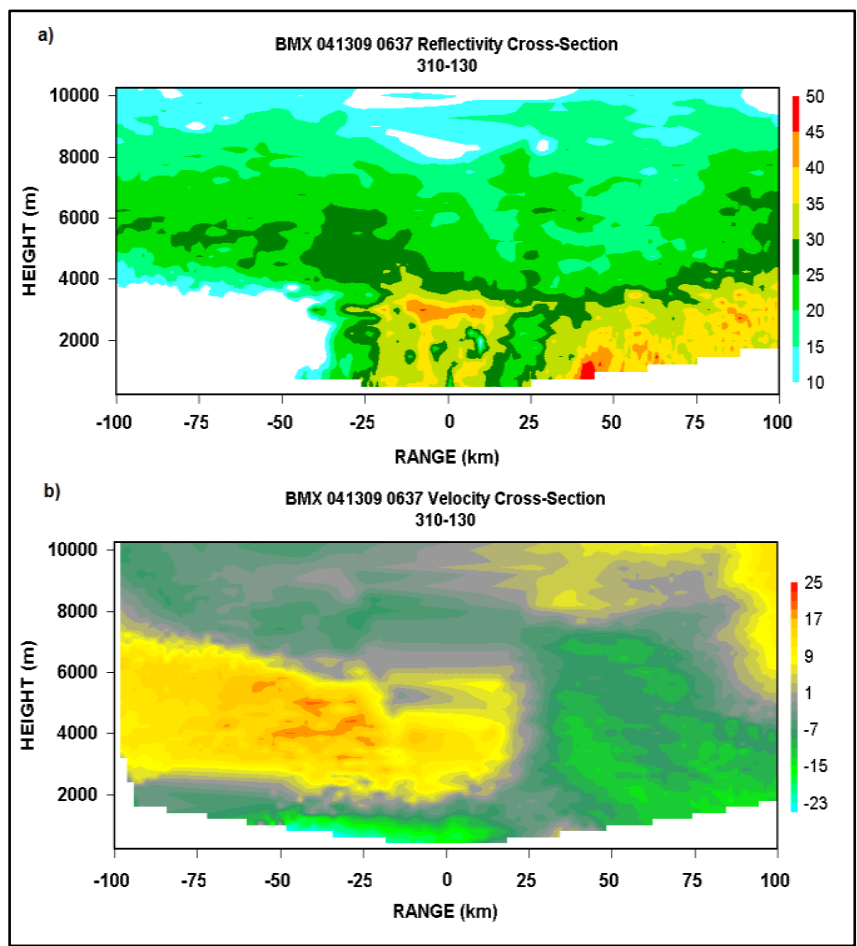

Figure 5. Cross section along the $310^{\circ}$ to $130^{\circ}$ azimuth of reflectivity (top, dBZ) and wave-parallel component of wind (radial velocity, bottom, $\mathrm{m} \mathrm{s}^{-1}$ ), analyzed at 0637 UTC 13 April 2009 from KBMX radar (see text).

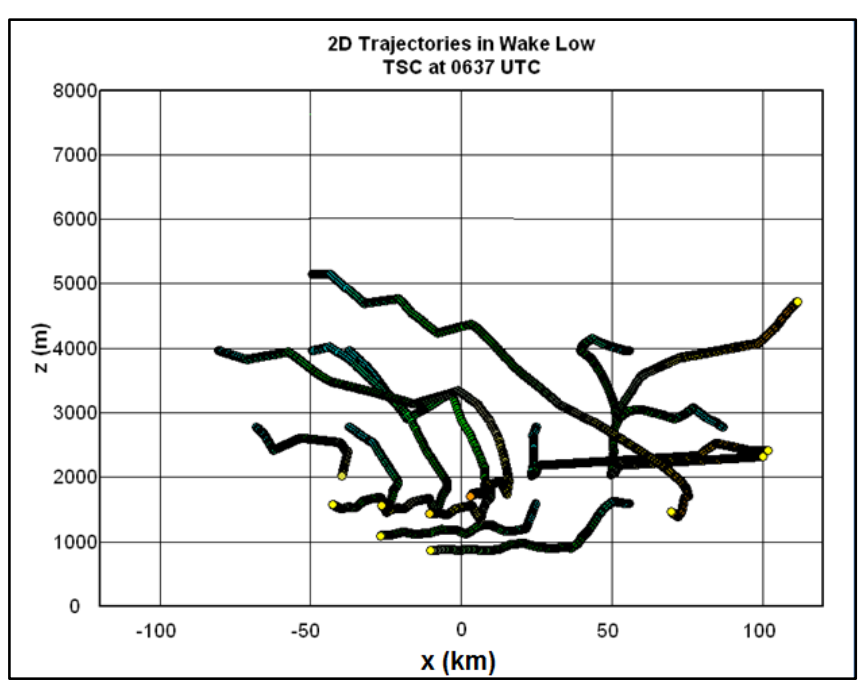

Figure 6. Two-dimensional trajectories for parcels starting at various positions at 0637 UTC 13 April 2009, using time-to-space conversion of radar velocity data (see text). The trajectories end at the yellow/orange circles.

vertically. This descent produced adiabatic warming and the surface low pressure perturbation. [In reality, the wake low is probably not steady-state, or "formpreserving," but because the parcel trajectories are generally over a short time period of about one hour, relative to the wake low lasting more than $12 \mathrm{~h}$, the assumption is valid.]

Taking the analysis one step further to determine whether the trajectories were reasonable, the 0600 UTC 13 April 2009 NAM model sounding at the KBMX radar site (not shown) was used, along with Eq. (1), to determine the net surface pressure change that should be associated with the descent of the parcels represented by the trajectories. Given the large amount of rainfall prior to 0600 UTC 13 April 2009, any non-saturated layers below $5 \mathrm{~km}$ were saturated and the temperature converted to the wet bulb temperature. Two well-defined trajectories show air parcels descending from approximately $4 \mathrm{~km}$ AGL to approximately $1.5 \mathrm{~km}$ MSL (Fig. 6), and used for the analysis. Numerically integrating the descent of each parcel and the associated surface pressure perturbation (see section 2), it was determined that a surface pressure drop of $8.9 \mathrm{hPa}$ would occur if the parcels descended and warmed adiabatically. This is close to the $8.0 \mathrm{hPa}$ pressure drop observed at Clay, Alabama. However, one must also consider that diabatic cooling owing to rainfall evaporation was not included, and this cooling would have reduced the warming and associated surface pressure fall somewhat. So, the trajectories showing large descent are consistent with the surface pressure perturbations.

\section{2) THE WAKE LOW OF 22 FebRUARY 1998}

A wake low with a classic radar signature propagated across much of Alabama on 22 February 1998. This event was first examined by Bradshaw et al. (1999) and then by CK11, and a PPI scan of radar reflectivity in this event is shown in Fig. 7a. Pressure falls up to $8 \mathrm{hPa}$ accompanied this wake low, with resultant winds producing widespread downed trees and structural damage. The peak wind gust at Birmingham, Alabama (KBHM), was $24.5 \mathrm{~m} \mathrm{~s}^{-1}$ (49 kt), but according to Bradshaw et al. (1999), wind damage at high elevations indicated wind gusts in excess of $30 \mathrm{~m}$ $\mathrm{s}^{-1}(60 \mathrm{kt})$. The RIJ was almost completely blocked in this intense wake low event, as shown in Fig. $7 b-c$. One reason for the large pressure falls was the depth of the low-level stable layer. In this case, the KBMX sounding (not shown) indicated an average BruntVäisälä frequency $\left(N=0.014 \mathrm{~s}^{-1}\right)$ up to $4 \mathrm{~km} \mathrm{MSL}$. Eq. (1) shows that deep layers with large $N$ values cause large pressure perturbations. However, this event is included primarily because of its extreme gradient in radar reflectivity (in a PPI scan) owing to 


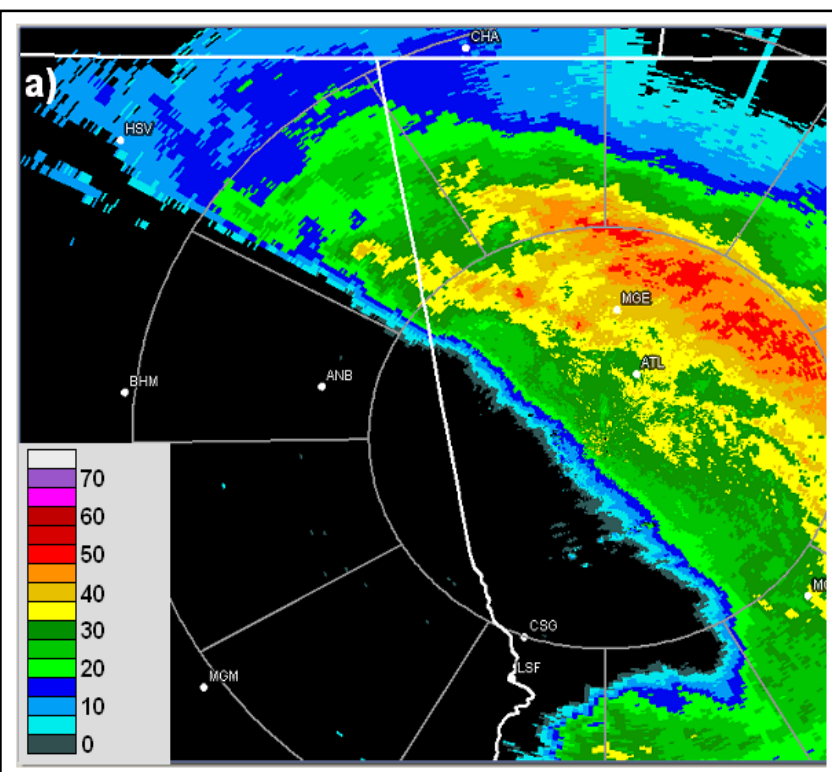

b)

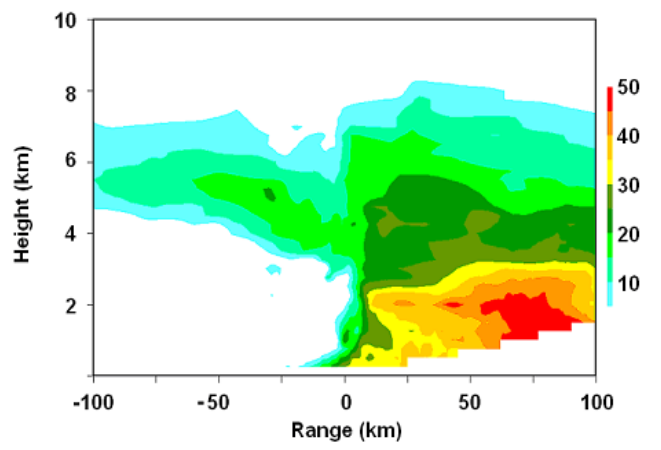

c)

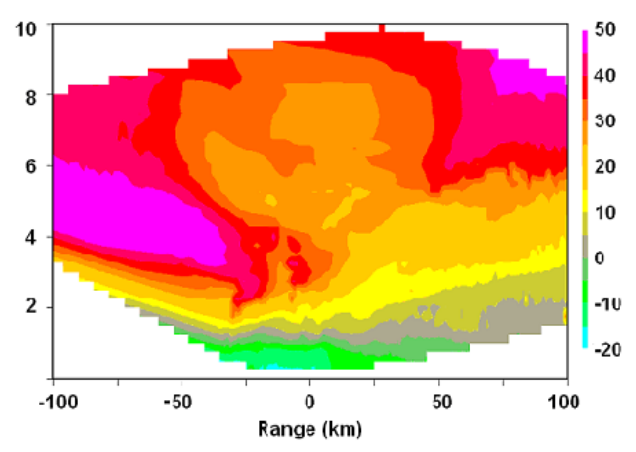

Figure 7. a) PPI scan of reflectivity (dBZ) at $0.5^{\circ}$ elevation from the Atlanta (KFFC) WSR-88D radar at 1808 UTC 22 February 1998. The wake low extends from near the radar site to the northwest near the $310^{\circ}$ azimuth. Range rings are at $100-\mathrm{km}$ spacing. Cross sections of b) reflectivity and c) radial velocity along azimuth $225^{\circ}$ to $45^{\circ}$ from the KFFC radar at 1808 UTC 22 February 1998 (see CK11).

subsidence at the back edge of an MCS, and the associated large pressure falls and wind speeds.

\section{3) SUMMARY OF POTENTIAL OPERATIONAL CLUES}

In cases like these, the operational meteorologist may have several clues of the potential for wake lows and damaging winds. First, a fairly sharp gradient in reflectivity at the back edge of an MCS is an initial indication that a descending RIJ may have developed. Second, radar cross sections of reflectivity and radial velocity-preferably normal to the back edge of the MCS and close to a single azimuth (because most of the wind perturbations are also normal to the back edge of the MCS and would be most consistent as radial velocity along a constant azimuth) - may show the descending, "blocked" RIJ. Third, because wake lows produce wind perturbations directed toward the back of the MCS, background winds aligned in the same general direction will make damaging winds more likely. Fourth, a stable layer at low-levels will allow for larger temperature perturbations owing to subsidence, and therefore a larger pressure perturbation in a wake low. Finally, mesonet observations of rapid pressure falls - or certainly reports of high wind speeds or wind damage, near the back edge of an MCS - are indicative a wake low has developed. These five operational clues are summarized in the schematic in Fig. 8.

\section{b. Solitary waves}

A solitary wave is a single wave of elevation or depression on the horizontal interface of two fluids with different density. A temperature inversion would be such an example, with much higher density cold air below, and lower density warm air above. Solitary waves move at constant velocity because of the balance between amplitude dispersion (larger amplitude waves move faster) and wavelength dispersion (longer wavelength waves move faster) (Christie et al. 1978).

Solitary waves are often attributable to the intrusion of a dense air mass (such as a cold pool) against a surface-based inversion (Christie et al. 1979). They also may form because of large-scale internal gravity waves, generated by processes including geostrophic adjustment, shear instability, and even leeside cold fronts (Lalas and Einaudi 1976; Uccellini and Koch 1987), perturbing the low-level stable layer. Solitary waves are most often seen as waves of elevation, but they may be characterized by multiple waves of elevation (and depression), with each successive wave becoming weaker (Bosart et al. 1998). Examples of long-lived solitary waves, some that impacted convec- 


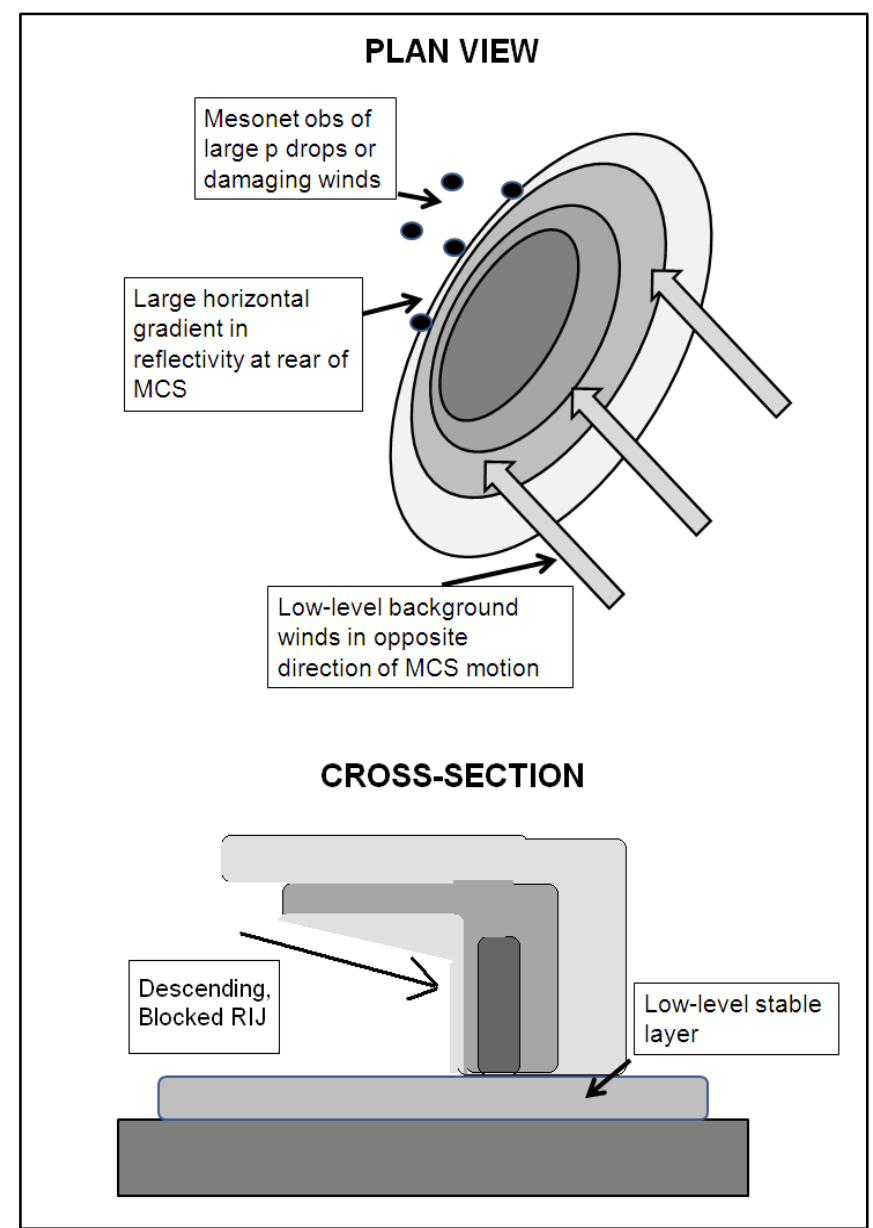

Figure 8. Schematic showing the five main operational clues pertaining to the forecasting and recognition of a wake low listed in section 3a.3. Shading indicates radar reflectivity.

tive storms, are discussed by many authors, including Brunk (1949), Tepper (1951), Stobie et al. (1983), Ferretti et al. (1988), and Koch et al. (1988). A wave of elevation in the atmosphere propagates as a temporary increase in the depth of a cool, stable layer. This uplift of the stable layer is shown in Fig. 9, a timeheight section of potential temperature from the UAH MPR. In the absence of diabatic heating, lines of constant potential temperature (isentropes) act like material surfaces, and show the temporary uplift in the stable layer. This increase in depth of a shallow cool layer, along with adiabatic cooling attributable to uplift, produces a temporary increase in surface pressure as the wave passes (Simpson 1997). Examples of theoretical surface pressure profiles associated with a solitary wave passage are shown in Fig. 10.

The full nonlinear impedance relationship (Coleman and Knupp 2010) shows that-all other things being equal — disturbances causing a pressure rise pro-

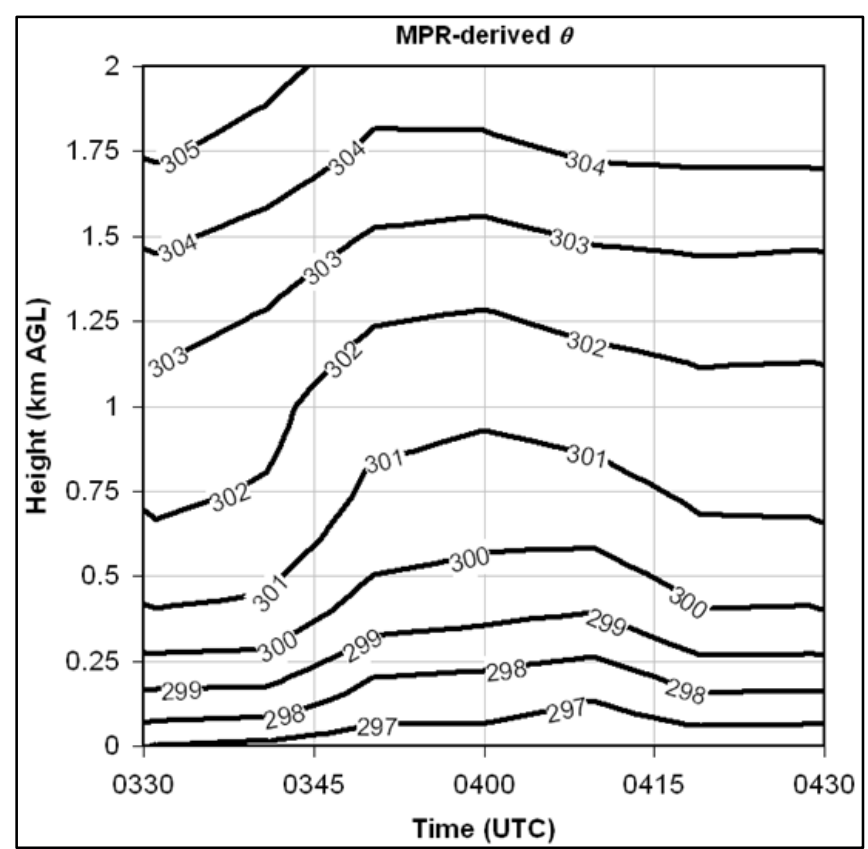

Figure 9. Time-height section of potential temperature calculated using microwave profiling radiometer data as a solitary wave passed on 26 June 2008 (from Coleman and Knupp 2011b).

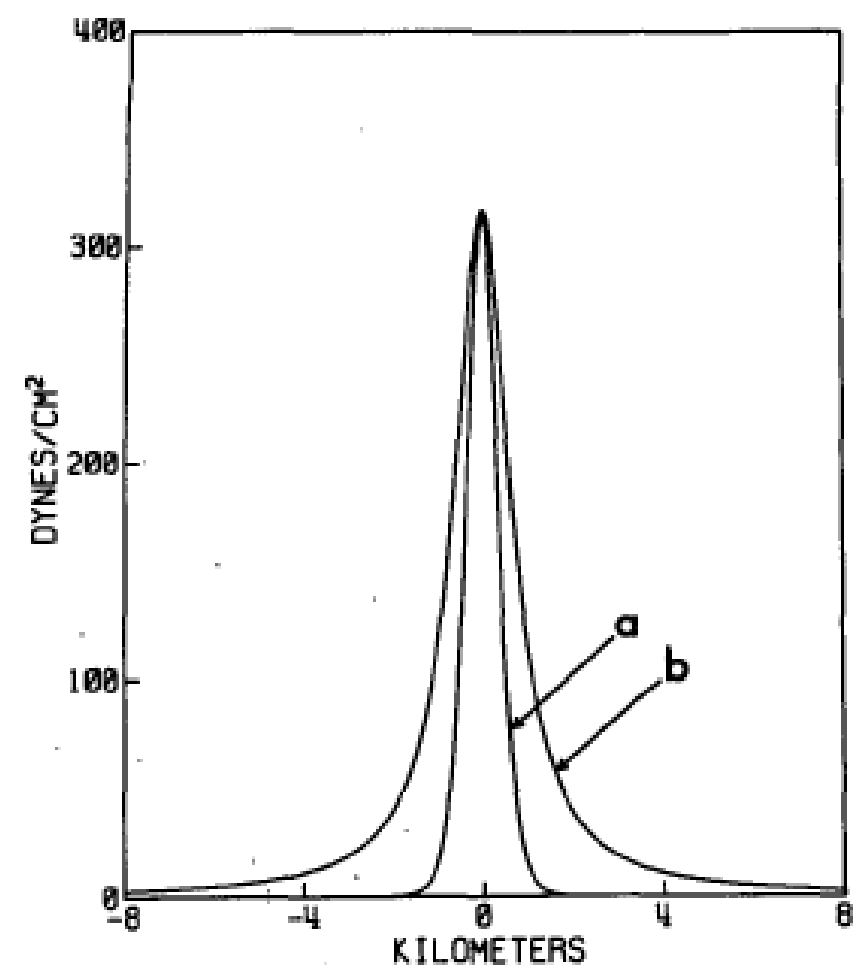

Figure 10. Surface pressure profiles associated with a solitary wave, given by two different theories (adapted from Christie et al. 1978).

duce larger wind perturbations than those causing a pressure fall with the relation: 


$$
u^{\prime}=\frac{\rho(c-U) \pm \sqrt{\rho^{2}(c-U)^{2}-2 \rho p^{\prime}}}{\rho}
$$

where $u^{\prime}$ is the perturbation wind speed, $\rho$ is the air density, $c$ is the speed of the propagating pressure disturbance, and $U$ is the component of the background wind in the direction of propagation. As Coleman and Knupp (2010) noted, the negative root of Eq. (2) in most cases is the only one that makes physical sense, so a positive $p$ ' creates a smaller value under the radical to be subtracted from the first term, and therefore a larger $u$ '.

Explaining this physically, in a disturbance causing a pressure fall, perturbation momentum (toward the back of the disturbance attributable to the "pulling" by low pressure) causes an air parcel to traverse the disturbance quickly. This means that an air parcel will not be exposed to the pressure disturbance as long, and will create smaller wind perturbations than those in a disturbance causing a pressure rise. The perturbation momentum in a transient pressure rise is in the direction of disturbance motion, causing an air parcel to be influenced by the pressure disturbance longer (Coleman and Knupp 2010). Therefore, solitary waves of elevation (having pressure increases) produce larger wind speeds than a disturbance of similar amplitude that causes a pressure decrease. This concept is explained more thoroughly in Coleman and Knupp (2010).

\section{1) THE SOLITARY WAVE OF 7 MARCH 2008}

On 7 March 2008, a soliton, or pair of solitary waves, formed along a surface-based cool layer near the back edge of a large area of precipitation over Mississippi and Alabama. The larger scale features of the waves and their environment were examined by Ruppert and Bosart (2014). The waves produced enhanced bands of radar reflectivity over Mississippi and Alabama. The primary wave produced measured wind gusts near $20 \mathrm{~m} \mathrm{~s}^{-1}(40 \mathrm{kt})$ and pressure perturbations of 4-5 hPa. Wind damage, including numerous downed trees, power outages, and some damaged structures, was reported in several Alabama counties (Elliott 2008a). The strong damaging winds in the wave prompted the NWS to issue a high wind warning.

The initial wave moved over the Birmingham, Alabama (KBMX), radar near 1055 UTC 7 March 2008. The PPI view of radar reflectivity (Fig. 11a) and
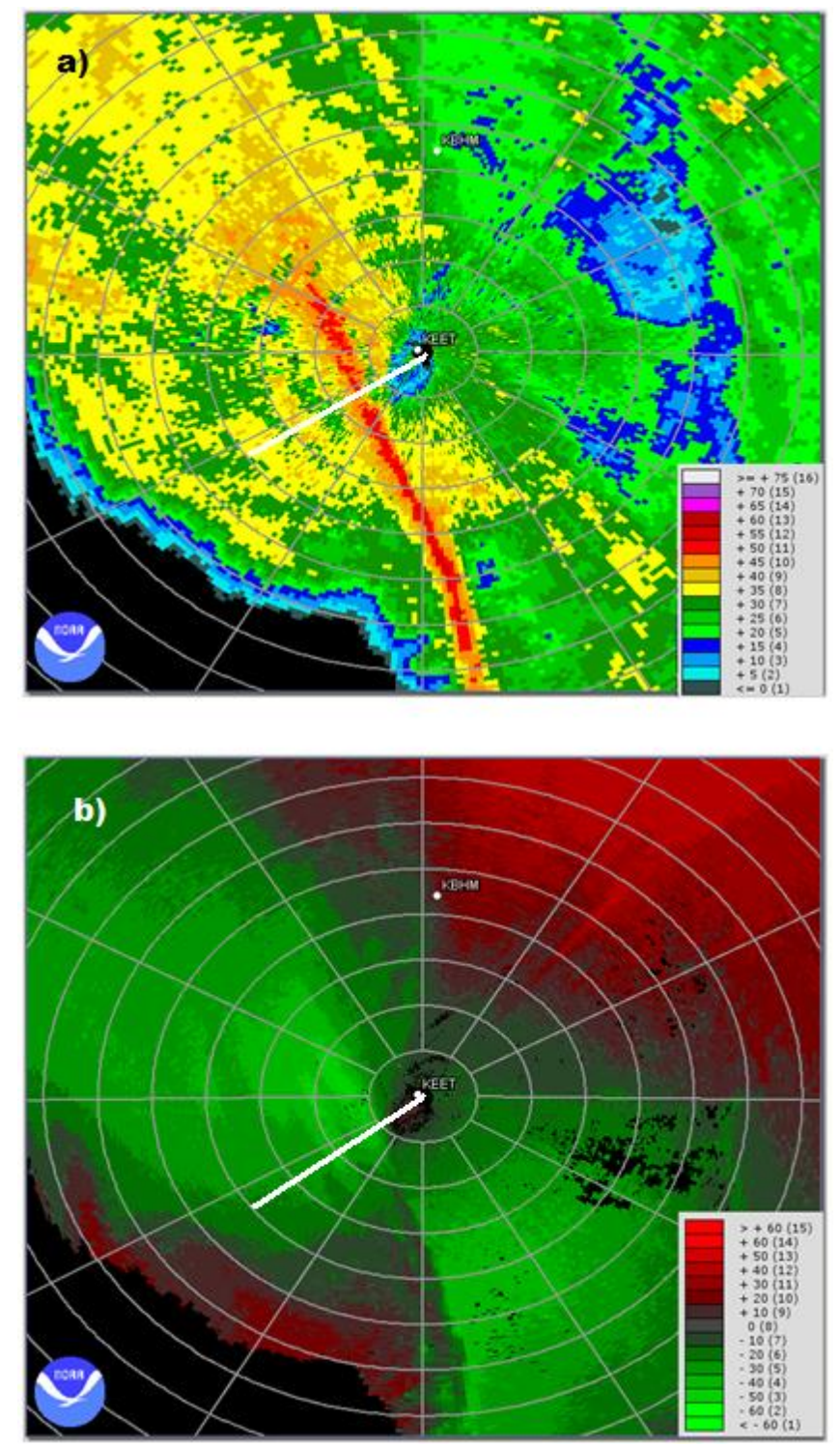

Figure 11. PPI scans at $0.5^{\circ}$ elevation of radar reflectivity (top, $\mathrm{dBZ}$ ) and radial velocity (bottom, kt) from the KBMX WSR-88D at 1045 UTC 7 March 2008. Range rings are at 10-km intervals. The white lines indicate the location of the vertical cross sections in Fig. 13.

radial velocity (Fig. 11b) at $0.5^{\circ}$ elevation at 1045 UTC 7 March 2008 showed the waves as they approached the radar. Low-level positive and negative perturbations in radial velocity appeared. Given that the majority of the perturbation winds in a solitary wave are in the direction of its motion, the large changes in radial velocity along the radial normal to the wave primarily result from winds normal to the radar (not tangential to it), and horizontal convergence and divergence was inferred. The horizontal convergence (divergence) was apparently associated with the maxima (minima) in radar reflectivity. The 0900 UTC 
7 March 2008 Eta Data Assimilation System model sounding at KEET - saturated to the wet-bulb temperature because of rain (Fig. 12) - shows a stable layer about $1100 \mathrm{~m}$ deep near the surface ahead of the wave.

Vertical cross sections of reflectivity and radial velocity along the direction of wave motion (from $235^{\circ}$ ) were retrieved (Fig. 13). Assuming a twodimensional wave (based on radar reflectivity and velocity data at multiple elevation angles, not shown), the radar velocity data were gridded, horizontal convergence calculated, then vertical motion calculated using a simple upward integration. This also is shown in Fig. 13. The intense band of reflectivity near the $-14 \mathrm{~km}$ range indicates that the strong upward motion (approaching $4 \mathrm{~m} \mathrm{~s}^{-1}$ near a range of $-11 \mathrm{~km}$ ) likely enhanced the rainfall, and it fell out just behind this region of maximum vertical motion. Downward motion, up to $-3.5 \mathrm{~m} \mathrm{~s}^{-1}$, occurred in the trough between the two waves. Upward motion around $3.2 \mathrm{~m} \mathrm{~s}^{-1}$ occurred with the second wave, but the reflectivity maximum was more diffuse. Note that in Fig. 13 the region of enhanced horizontal winds (indicated by inbound radial velocity, blue color) associated with the soliton was fairly shallow, confined mainly below 1.3 $\mathrm{km}$ AGL. Because the winds were produced by the hydrostatic increase in pressure when the stable layer near the surface was lifted, it is to be expected that the largest horizontal pressure gradients in the solitary wave would be near the surface. Wind perturbations within the lead wave were significant, with a region about 3-km wide and up to almost $300 \mathrm{~m}$ AGL having radial velocities near $20 \mathrm{~m} \mathrm{~s}^{-1}$ (40 kt). The secondary wave had a smaller area of radial velocities of 17-20 $\mathrm{m} \mathrm{s}^{-1}(34-40 \mathrm{kt})$.

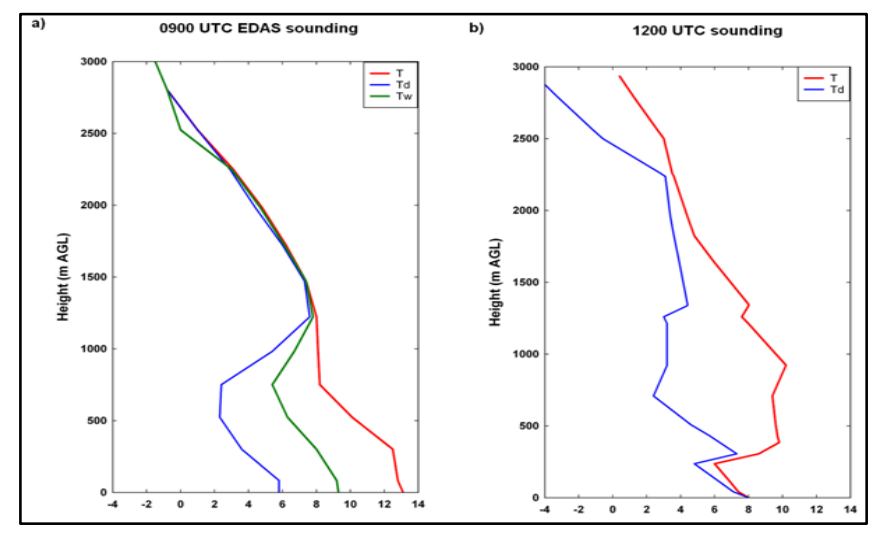

Figure 12. Profiles of temperature (red), dewpoint (blue), and wet bulb temperature (green), all in ${ }^{\circ} \mathrm{C}$, from the 0900 UTC 7 March 2008 Eta Data Assimilation System model sounding at KEET. The more stable boundary layer extending up to $1100 \mathrm{~m}$ AGL may be inferred from the wet bulb temperature in panel a).

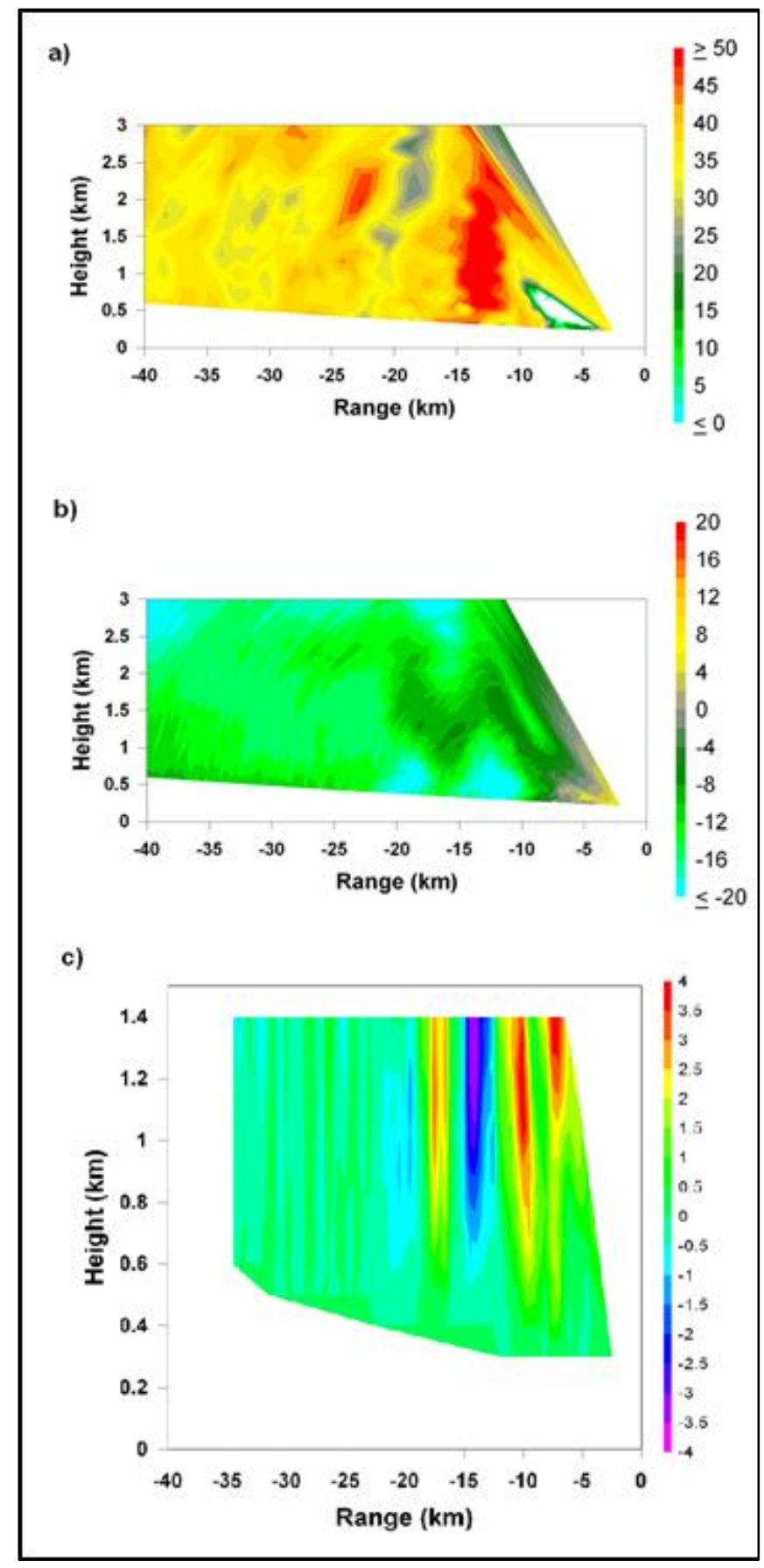

Figure 13. Vertical cross sections of a) reflectivity (dBZ), b) radial velocity $\left(\mathrm{m} \mathrm{s}^{-1}\right)$, and c) vertical velocity $\left(\mathrm{m} \mathrm{s}^{-1}\right)$ from KBMX at 1045 UTC on 7 March 2008 along azimuth $235^{\circ}$, approximately the direction the wave was approaching from.

Using time-to-space conversion of radar data along azimuth $250^{\circ}$ at 1045 UTC 7 March 2008, and assuming a form-preserving, steady state wave with a constant speed, a trajectory of an air parcel starting near the top of the stable layer (500 m AGL) was determined (Fig. 14). The parcel moved northeastward 


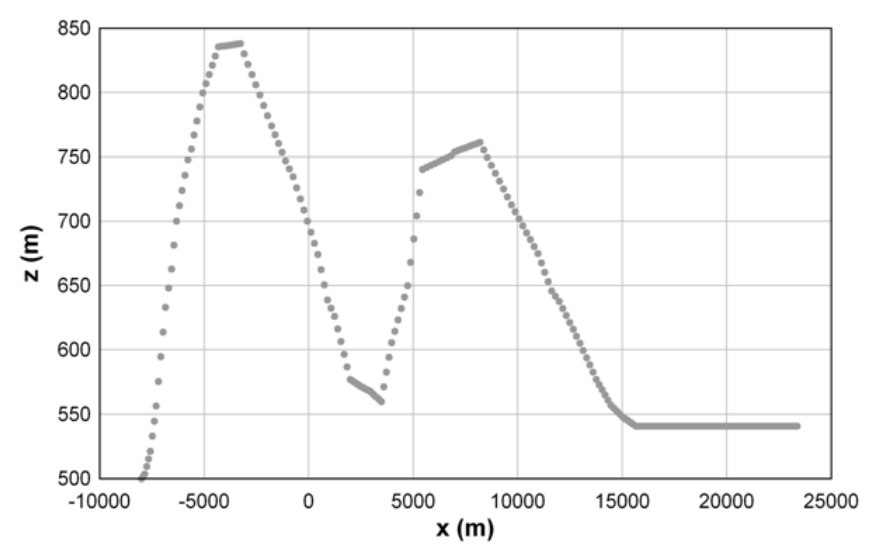

Figure 14. Trajectory of a parcel along azimuth $235^{\circ}$ that begins about $1 \mathrm{~km}$ horizontally ahead of the wave at $500 \mathrm{~m}$ AGL at 1045 UTC on 7 March 2008. The parcel is moving from left to right in this figure.

along with the wave. The trajectory showed that the parcel rose quickly to near $840 \mathrm{~m}$ AGL as the main wave passed, temporarily descended to $555 \mathrm{~m}$ AGL, and then rose again to about $760 \mathrm{~m}$ AGL within the second wave.

Surface data in Fig. 15 show the classical hyperbolic, temporary increase in pressure typically associated with a solitary wave. The pressure increase associated with the entire soliton was about $4 \mathrm{hPa}$, but there was not a large signal of a primary and a secondary wave in the pressure trace. Note the component of the 2-min average wind $u$ in the direction of wave motion increased very quickly and was correlated with $p$, consistent with the impedance relations (Gossard and Hooke 1975; Coleman and Knupp 2010). Wind speeds increased to about $13 \mathrm{~m} \mathrm{~s}^{-1}(26 \mathrm{kt})$. The 5 -s wind gusts near $19 \mathrm{~m} \mathrm{~s}^{-1}$ (38 kt) occurred just ahead of the center of the main wave. In this case, the component of ambient winds in the direction of wave motion $(U)$ ahead of the solitary wave were negative, or from the northeast. Therefore, the perturbation winds $\left(u^{\prime}\right)$ were in the opposite direction of $U$, likely decreasing the net surface winds $(u)$ somewhat.

\section{2) SUMMARY OF POTENTIAL OPERATIONAL CLUES}

Summarizing operational clues that may indicate that a solitary wave is producing significant winds include a) a steady, quasi-linear band of enhanced radar reflectivity, b) one or more bands of enhanced Doppler radial velocities superimposed over the band(s) of reflectivity, c) possibly weaker bands of enhanced reflectivity and radial velocity behind the main band, d) large, temporary pressure perturbations along the reflectivity band, and e) ideally, a reflectivity band in an

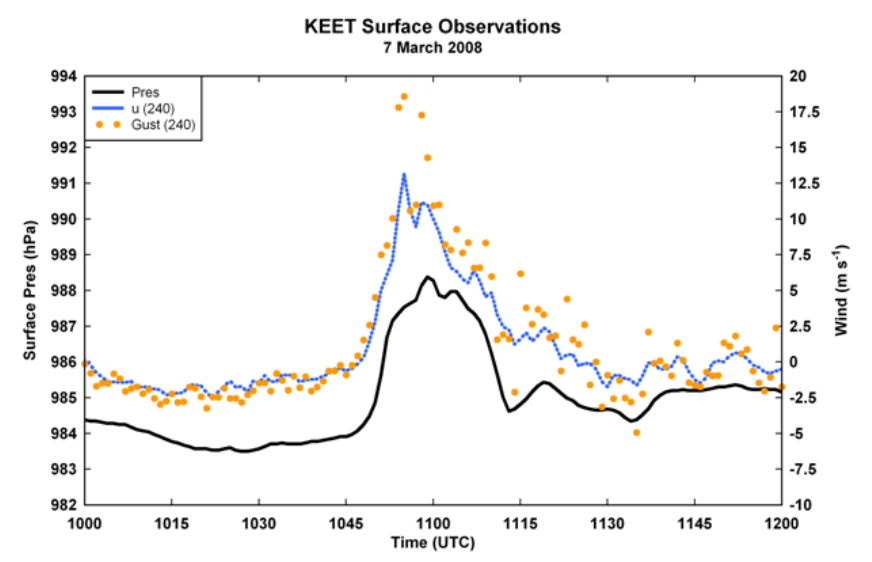

Figure 15. Surface observations from the ASOS at Calera, AL (KEET, only $4 \mathrm{~km}$ northwest of the KBMX WSR-88D), of surface pressure ( $\mathrm{hPa}$, solid curve), the component of the 2-min average wind speed in the direction of the wave motion ( $\mathrm{m} \mathrm{s}^{-1}$, blue curve), and the component of the 5-s wind gust in the direction of wave motion ( $\mathrm{m} \mathrm{s}^{-1}$, orange dots) on 7 March 2008.

environment with a background wind in the same direction as the motion of the wave. In the 7 March 2008 case, the wave motion was $25 \mathrm{~m} \mathrm{~s}^{-1}$, so clearly high winds can come from fast-moving waves; but the background wind was in the opposite direction of wave motion, partially cancelling some of the ageostrophic wind produced by the wave. Thus, although the background wind in the same direction as wave motion is not necessary for damaging winds, such a condition could enhance surface winds produced by weaker waves (in amplitude of pressure perturbation).

\section{c. Cold fronts}

Cold frontal passages are often accompanied by gusty winds, but not typically with wind speeds that are considered severe. However, when the cold frontal surface is exceptionally steep along its leading edge, the sudden increase in hydrostatic pressure produced at the surface by the rapid increase in density of the atmosphere over a deep column may produce a strong horizontal pressure gradient and associated damaging winds (Kapela et al. 1995). In a steep cold front, the winds are typically not geostrophic or even semigeostrophic (Bluestein 1993), but instead blow across the isobars at a sharp angle from high to low pressure. In such cases, the impedance relations for pressure disturbances are best suited to determine the potential wind speed at the surface. Once again, because a cold front like this produces a rapid increase in pressure, the nonlinear impedance relation indicates that higher wind speeds may be achieved than would be possible in a rapid decrease in pressure of similar amplitude. In 
addition, when the isentropes are very steep (the lapse rates are nearly adiabatic), higher winds front aloft are mixed down to the surface more readily (Kapela et al. 1995).

\section{1) THE COLD FRONT OF 30 JANUARY 2008}

On 30 January 2008, a strong cold front moved through the southeastern United States. The strong anticyclone associated with the cold air caused a very large pressure gradient and gusty winds (Fig. 16). According to NWS (2008), wind damage - including trees and power lines being blown down-was reported over numerous counties in northern and central Alabama near or shortly after frontal passage. Some official observations of the peak wind gust associated with this cold front over central Alabama included 24 $\mathrm{m} \mathrm{s}^{-1}$ (48 kt) at Birmingham (KBHM), $21 \mathrm{~m} \mathrm{~s}^{-1}$ (42 kt) at Calera (KEET), and $17.5 \mathrm{~m} \mathrm{~s}^{-1}(35 \mathrm{kt})$ at Tuscaloosa (KTCL) and Anniston (KANB). The highest observed wind gust was $29 \mathrm{~m} \mathrm{~s}^{-1}$ (58 kt, Elliott 2008b), on top of a building in downtown Birmingham, indicating stronger winds aloft over areas with high roughness length. Elliott (2008b,c,d) reported "literally hundreds of trees" uprooted across Alabama, with trees falling on at least three homes; numerous roads became blocked by fallen trees, and at least one automobile accident occurred involving a collision with a tree. These winds were directly associated with the cold front itself, as opposed to convection. Such wind speeds are quite unusual for the passage of a cold front without any significant deep convection over the eastern United States.

However, as shown in Fig. 17a, there was a very rapid increase in pressure at $\mathrm{UAH}$ as the front passed; the pressure climbed $2 \mathrm{hPa}$ in $4 \mathrm{~min}$. In a case with a near-discontinuity in pressure like this one, the impedance relation is the best method for estimating maximum surface winds. If one applies the standard isallobaric wind relation (e.g., Bluestein 1993; Rochette and Market 2006), the wind estimate varies greatly depending on the horizontal scale chosen. For example, on the meso- $\gamma$ scale (where most of the damaging winds occurred), wind estimates $>100 \mathrm{~m} \mathrm{~s}^{-1}$ were calculated. Only a meso- $\alpha$ scale analysis of the isallobaric wind produced reasonable estimates. Because the primary zone of damaging winds associated with the front was $<25 \mathrm{~km}$ wide, a meso- $\alpha$ scale analysis is not appropriate in this case. Therefore, the isallobaric wind is of limited use for small-scale disturbances producing near-discontinuities in pressure,

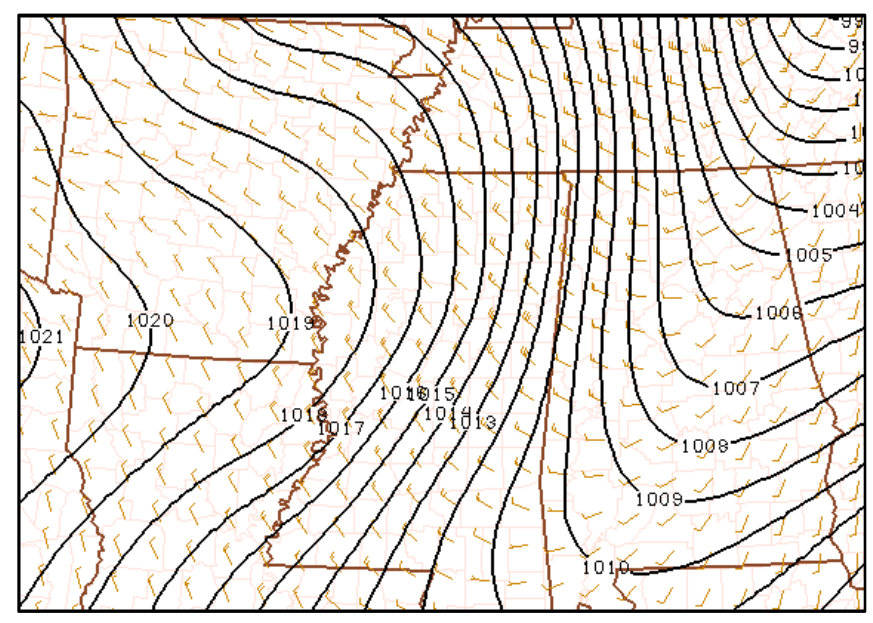

Figure 16. Contours of mean sea level pressure (dark solid, hPa) and wind barbs (brown, kt) over the southeastern United States at 0300 UTC 30 January 2008 (from SPC mesoanalysis). Note that the winds are nearly perpendicular to the isobars.
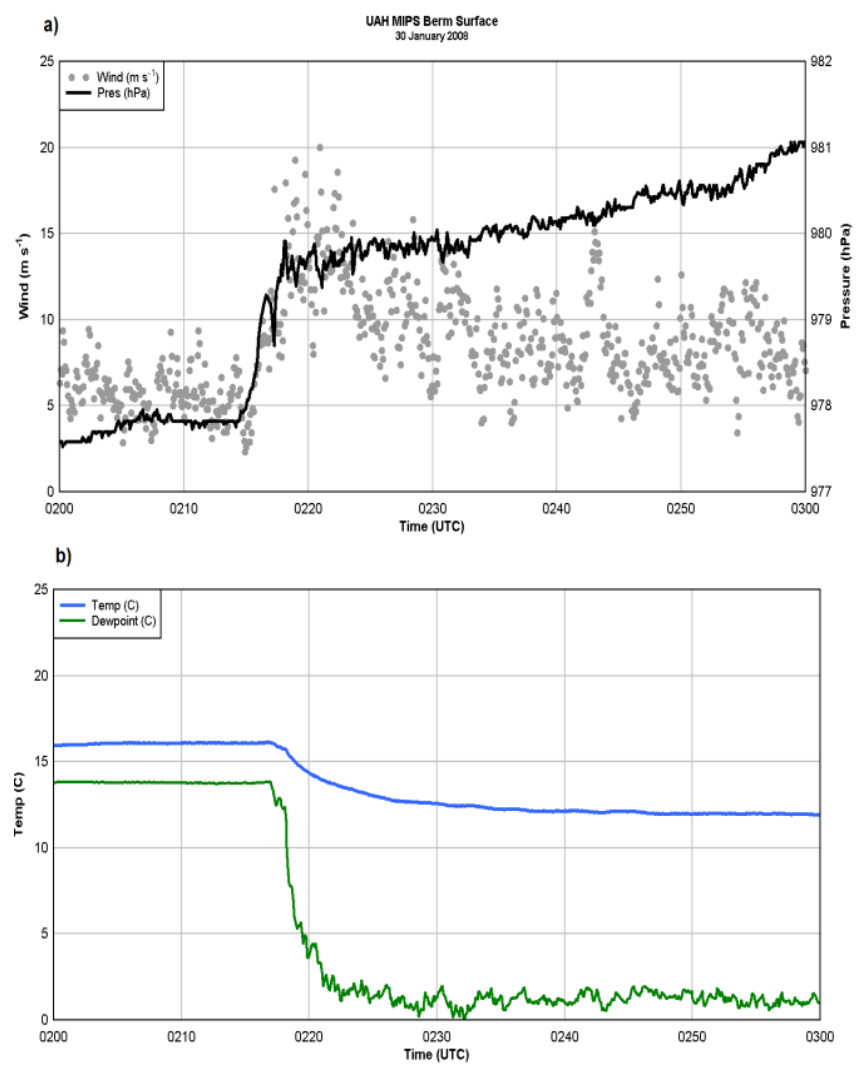

Figure 17. Time series of (a) pressure (solid, hPa) and 5-s winds (dotted, $\mathrm{m} \mathrm{s}^{-1}$ ) and (b) temperature $\left({ }^{\circ} \mathrm{C}\right.$, blue) and dewpoint $\left({ }^{\circ} \mathrm{C}\right.$, green) at UAH on 30 January 2008.

and the impedance relations provide better wind estimates. Also, the temperature dropped $2.3^{\circ} \mathrm{C}\left(4.3^{\circ} \mathrm{F}\right)$ in $5 \mathrm{~min}$, and the dewpoint dropped $12^{\circ} \mathrm{C}\left(22^{\circ} \mathrm{F}\right)$ coincident with the pressure rise (Fig. 17b). 


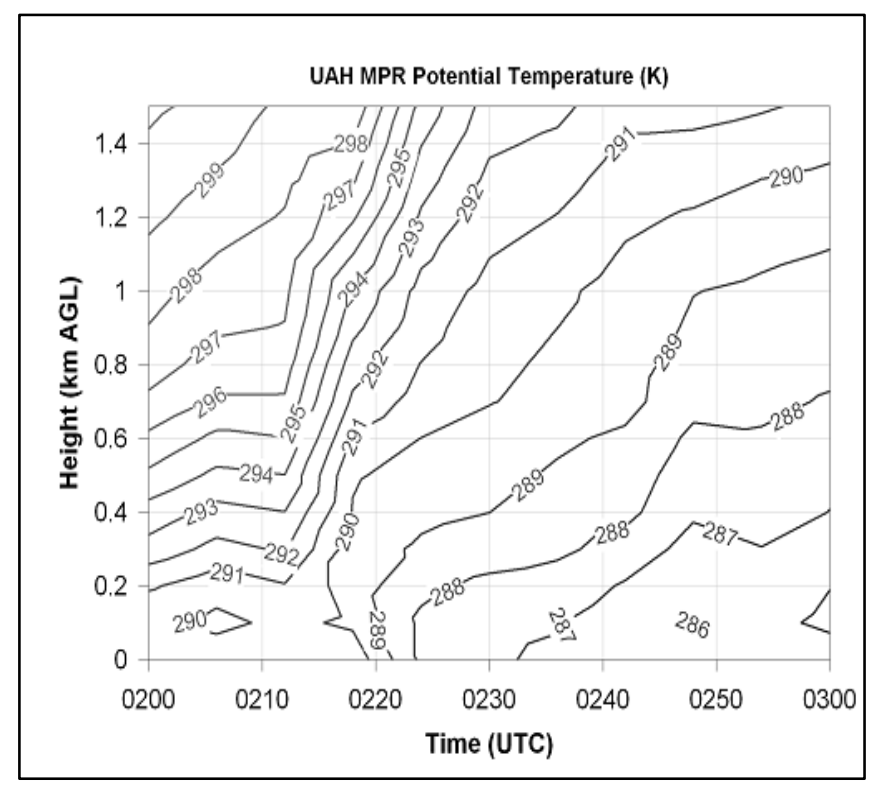

Figure 18. Time-height section of potential temperature $(\mathrm{K})$ from microwave profiling radiometer data at UAH on 30 January 2008.

In this case, the cold frontal surface was exceptionally steep. In other words, the frontal passage occurred over a fairly deep layer almost simultaneously. The best illustration of the nearly vertical nature of this cold front is shown in Fig. 18, a time-height section of potential temperature at UAH derived from MPR data. Note the very steep and nearly vertical isentropes from 295 to $291 \mathrm{~K}$, at least up to $1.5 \mathrm{~km}$ AGL. Surface data show that the wind shift (indicating frontal passage) occurred at 0216 UTC 30 January 2008. The potential temperature dropped $4^{\circ} \mathrm{C}$ at $1 \mathrm{~km}$ AGL in $8 \mathrm{~min}$, between 0210 and 0220 UTC 30 January 2008. The forward speed of the front was determined to be $c=$ $17.5 \mathrm{~m} \mathrm{~s}^{-1}$, so using a simple time-to-space conversion, this indicated a horizontal potential temperature gradient of $0.5 \mathrm{~K} \mathrm{~km}^{-1}$ at $1 \mathrm{~km} \mathrm{AGL}$. This "wall" of cold air resulted in the rapid increase in pressure owing to the rapid increase in density above the surface over a deep layer.

Given that the background wind in the direction of frontal motion, $U$, was $1.5 \mathrm{~m} \mathrm{~s}^{-1}, p^{\prime}=2 \mathrm{hPa}$, and the surface air density calculated to be $1.17 \mathrm{~kg} \mathrm{~m}^{-3}$, the nonlinear impedance relation provides an estimate for the surface wind of $13.1 \mathrm{~m} \mathrm{~s}^{-1}(26 \mathrm{kt})$. Observations at UAH included a maximum 2-min wind speed of 14.8 $\mathrm{m} \mathrm{s}^{-1}(30 \mathrm{kt})$, fairly consistent with the impedance relation, while the maximum gust was $20 \mathrm{~m} \mathrm{~s}^{-1}$ (40 kt). The nearly vertical isentropes also indicate that the air was less stable than along typical fronts, because potential temperature increased little with height. So, the potential for mixing higher wind speeds from aloft down to the surface was increased with the steep front.

\section{2) SUMMARY OF POTENTIAL OPERATIONAL CLUES}

Cold fronts that are exceptionally steep and have the potential to produce damaging winds may be identified in several ways. One can look at the amplitude and duration of pressure rises in 1-min Automated Surface Observing System (ASOS) data as the cold front passes by upstream stations, high wind gusts in METAR observations, or damage in local storm reports. In trying to anticipate high winds along a cold front farther in advance, one may examine isobaric charts for large pressure gradients, and isallobaric charts for rapid pressure rises (Kapela et al. 1995). Steep lapse rates, often nearly dry adiabatic, also indicate nearly vertical isentropes and the ability for higher momentum air to mix down to the surface more effectively (Kapela et al. 1995). In addition, one may look at model cross sections of potential temperature (normal to the front) and note whether or not the isentropes are very steep or vertical. On 30 January 2008, a NAM model cross section through the cold front showed nearly vertical isentropes near the leading edge of the front, up to $1 \mathrm{~km}$ MSL (Fig. 19). The NAM model did not resolve the total depth of the nearly vertical isentropes, nor the extreme temperature gradient, but it did provide a general clue of a front with a steep slope. Perhaps a higher-resolution model would resolve the horizontal gradient more effectively. One may also examine plan-view maps of the cold front, using either temperature or wind observations. In Fig. 20, 0000 UTC 30 January 2008 model analyses of 1000-, 925-, and 850-hPa temperature are shown. The cold front is near the same location at all three levels, indicating cold advection is occurring over a deep layer, and causing the steep nature of the front and rapid pressure rise (Kapela et al. 1995). Here, the cold front does not slope further northwest with height (as one would expect with a cold front with a more typical slope), but instead shows up at the same horizontal location at each height. Finally, nearly unidirectional winds at low-levels indicate a very wellmixed boundary layer, and the possibility that nearly vertical isentropes are allowing strong downward mixing of winds from aloft (Kapela et al. 1995).

\section{Summary and discussion}

In this paper, we discussed three types of atmospheric phenomena that produce wind damage, but are 


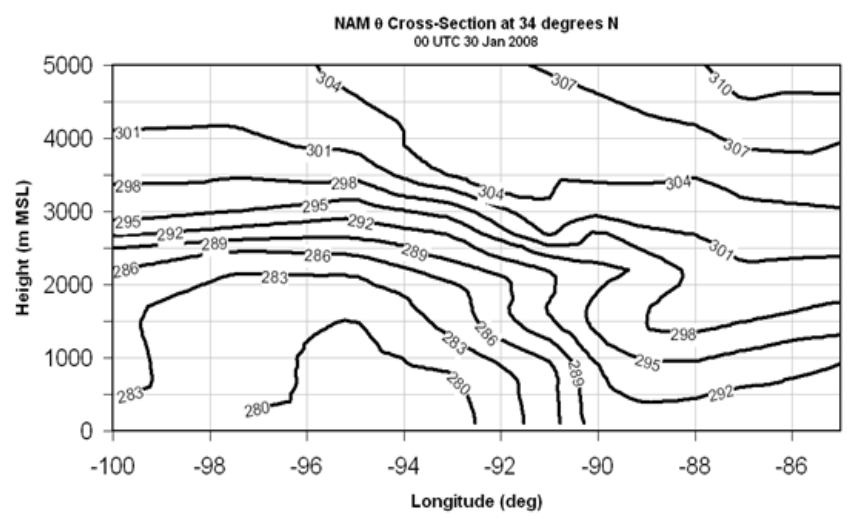

Figure 19. Cross section of potential temperature $(\mathrm{K})$ according to the NAM model at 0000 UTC 30 January 2008 , along $34^{\circ} \mathrm{N}$.

not the typical severe convective storms thought of as producing wind damage (tornadoes and severe thunderstorms). The impedance relation indicates that the wind perturbations associated with transient pressure disturbances, such as those discussed in this paper, are proportional to the amplitude of the pressure disturbance and inversely proportional to the intrinsic speed of the disturbance. One must take into account the ambient low-level winds to determine the total wind in the disturbance. If the ambient wind is in the same (opposite) direction as the perturbation wind, winds will be higher (lower).

Wake lows are probably the most commonly observed of these phenomena, and are generally associated with a blocked, descending RIJ at the rear of a QLCS. The descending air warms adiabatically and produces an area of surface low pressure. This low pressure area is more intense if the air at low levels is stable, and may explain why wake lows are sometimes mistakenly interpreted as gravity waves. Air flows into the area of low pressure from front to back, usually causing winds with an easterly component. Trees are more vulnerable to falling during easterly strong winds because they do not receive these nearly as often, so wake lows are very efficient at downing trees. In wake lows and in other events causing strong winds, it is well-known that wet soils allow more trees to fall.

Solitary waves are long-term, balanced, waves of elevation or depression that propagate along a temperature inversion or the top of a very stable layer. Waves of elevation are probably the most commonly observed significant weather phenomena. The sudden lifting of the stable layer produces an increase in the depth of the stable layer, adiabatic cooling, and high pressure at the surface. These waves may achieve pressure perturbations as high as $5 \mathrm{hPa}$, and the transient pressure
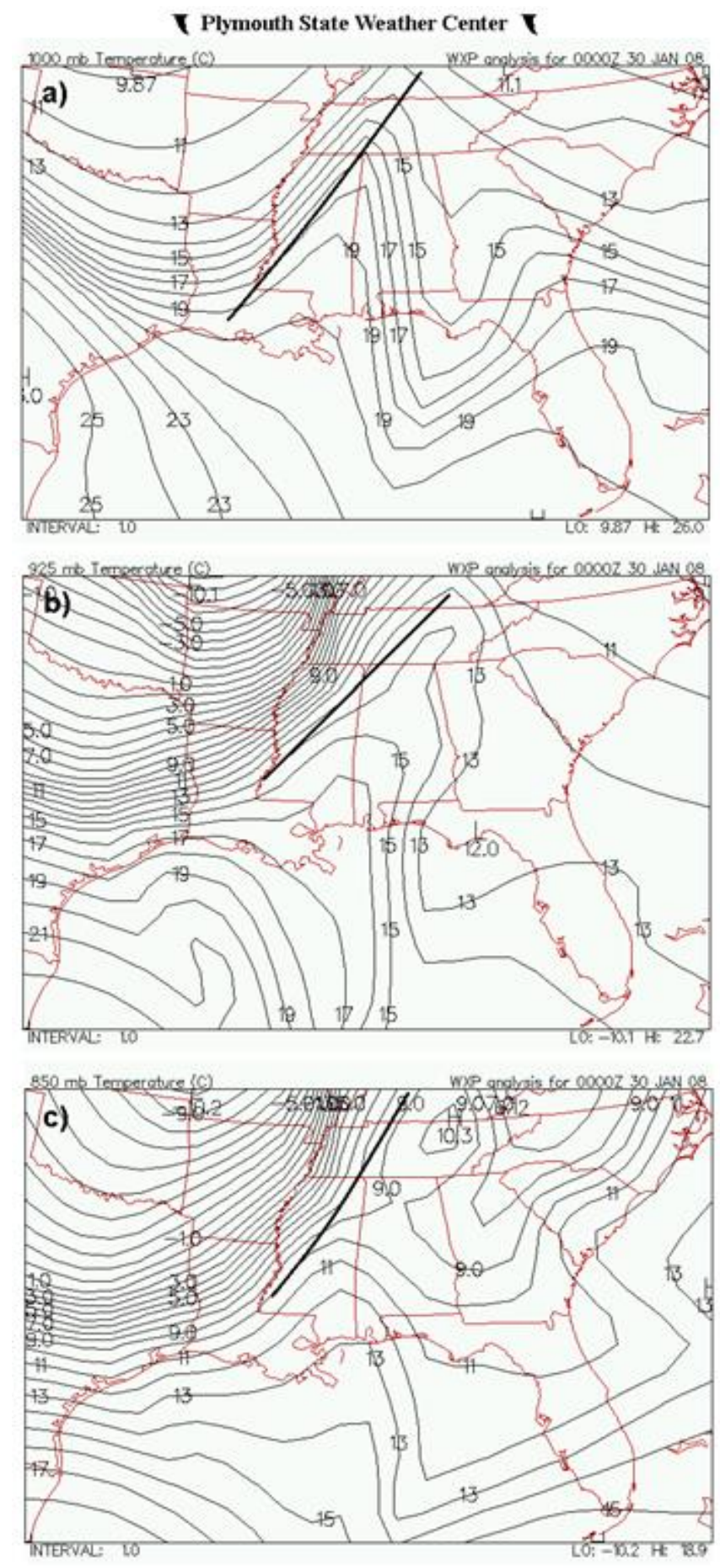

Figure 20. Analysis of temperature $\left({ }^{\circ} \mathrm{C}\right)$ over the southeastern U.S. at 0000 UTC 30 January 2008. The location of the cold front is indicated by the heavy black curve.

gradient may produce damaging winds. Because of effects described in the nonlinear impedance relation (section 3b), relatively higher wind speeds occur owing to similar amplitude pressure perturbations in pressure jumps than in pressure drops. 
Finally, some cold fronts are very steep and cause large and rapid pressure jumps. The winds become highly ageostrophic and are directed nearly perpendicular to the isobars, from the high pressure produced hydrostatically by the dense cold air behind the front, towards the low pressure ahead of the front. In some cases, surface pressures may rise $\sim 2 \mathrm{hPa}$ in $5 \mathrm{~min}$. This may produce damaging winds associated with some cold fronts that develop large temperature gradients over a deep layer.

Each of these phenomena, as shown using case studies, may produce widespread wind damage-in some cases comparable to bow echoes or severe thunderstorms. They are also a threat to aviation. Because they are not the typical phenomena that produce damaging winds, forecasters must be vigilant in watching for such phenomena. Reports of wind gusts or wind damage at the rear of an MCS, or a sharp cutoff in the rainfall on radar, are strong indicators of a wake low. A relatively fast-moving linear maximum in reflectivity accompanied by pressure jumps and traveling on a stable layer should be watched for the possibility of a solitary wave and its associated high winds. Cold fronts that are very steep in slope-often indicated by maps showing the location of the cold front being approximately the same (horizontally) up to a depth of 925 or even $850 \mathrm{hPa}$, especially those where winds are blowing across the isobars at a large angle approaching $90^{\circ}$ - should be watched closely for wind damage.

Acknowledgments. This research was completed under NSF grant AGS-1359771. The authors thank Ryan Wade and Tony Lyzaa of UAH, and Mike Coniglio (NSSL) for discussions on isallobaric winds. We also thank the reviewers, John Knox (Univ. of Georgia) and Ken Cook (NWS), and one anonymous reviewer, whose comments improved the manuscript significantly. The authors acknowledge the contributions of J. B. Elliott (1932-2015), a good man whose damage information gathering greatly helped this paper, and whose voice on NOAA Weather Radio in Alabama from 1977 through 1989 saved many lives and contributed to the career of the lead author and one of the reviewers.

\section{REFERENCES}

Bluestein, H. B., 1993: Synoptic-Dynamic Meteorology in Midlatitudes. Oxford University Press, 594 pp.

Bosart, L. F., and A. Seimon, 1988: A case study of an unusually intense atmospheric gravity wave. Mon. Wea. Rev., 116, 1857-1886, Crossref.
W. E. Bracken, and A. Seimon, 1998: A study of cyclone mesoscale structure with emphasis on a largeamplitude inertia-gravity wave. Mon. Wea. Rev., 126, 1497-1527, Crossref.

Bradshaw, J. T., R. A. Murphy, and K. J. Pence, 1999: The Alabama gravity wave event of February 22, 1998: A classic mesoscale forecasting challenge. Preprints, Eighth Conf. on Mesoscale Processes. Boulder, CO, Amer. Meteor. Soc., 357-360.

Brunk, I. W., 1949: The pressure pulsation of 11 April 1944. J. Meteor., 6, 181-187, Crossref.

Chaney, W. R., 2001: How wind affects trees. Indiana Woodland Steward, 10 (1). [Available online at woodlandsteward.squarespace.com/storage/pastissues/windaffe.htm.]

Christie, D. R., K. J. Muirhead, and A. L. Hales, 1978: On solitary waves in the atmosphere. J. Atmos. Sci., 35, 805-825, Crossref.

1979: Intrusive density flows in the lower troposphere: A source of atmospheric solitons. $J$. Geophys. Res., 84, 4959-4970, Crossref.

Coleman, T. A., 2008: The interactions of gravity waves with mesocyclones and tornadoes. Ph.D. dissertation, The University of Alabama in Huntsville, $220 \mathrm{pp}$.

, and K. R. Knupp, 2008: The interactions of gravity waves with mesocyclones: Preliminary observations and theory. Mon. Wea. Rev., 136, 4206-4219, Crossref. , and __, 2009: Factors affecting surface wind speeds in gravity waves and wake lows. Wea. Forecasting, 24, 1664-1679, Crossref.

, and _ 2010: A nonlinear impedance relation for the surface winds in pressure disturbances. J. Atmos. Sci., 67, 3409-3422, Crossref.

, and _ 2011a: A review of three significant wake lows over Alabama and Georgia. Wea. Forecasting, 26, 766-773, Crossref.

, and __ 2011b: Radiometer and profiler analysis of the effects of a bore and a solitary wave on the stability of the nocturnal boundary layer. Mon. Wea. Rev., 139, 211-223, Crossref.

Doviak, R. J., and R. Ge, 1984: An atmospheric solitary gust observed with a Doppler radar, a tall tower and a surface network. J. Atmos. Sci., 41, 2559-2573, Crossref.

Elliott, J. B., 2008a: Gravity wave damage. [Available online at www.alabamawx.com/?p=5964.]

, 2008b: Latest on the high wind. [Available online at www.alabamawx.com/?p=5251.]

, 2008c: Fast incoming reports. [Available online at www.alabamawx.com/?p=5248.]

, 2008d: At the midnight hour. [Available online at www.alabamawx.com/?p=5252.]

Eom, J. K., 1975: Analysis of the internal gravity wave occurrence of 19 April 1970 in the Midwest. Mon. Wea. Rev., 103, 217-226, Crossref. 
Ferretti, R., F. Einaudi, and L. W. Uccellini, 1988: Wave disturbances associated with the Red River Valley severe weather outbreak of 10-11 April 1979. Meteor. Atmos. Physics, 39, 132-168, Crossref.

Fujita, T. T., 1955: Results of detailed synoptic studies of squall lines. Tellus, 7, 405-436, Crossref.

Gaffin, D. M., 1999: Wake low severe wind events in the Mississippi River Valley: A case study of two contrasting events. Wea. Forecasting, 14, 581-603, Crossref.

Gallus, W. A., and R. H. Johnson, 1995: The dynamics of circulations within the trailing stratiform regions of squall lines. Part I: The 10-11 June PRE-STORM system. J. Atmos. Sci., 52, 2161-2187, Crossref.

, 1996: The influence of microphysics in the formation of intense wake lows: A numerical modeling study. Mon. Wea. Rev., 124, 2267-2281, Crossref.

Gossard, E. E., and W. H. Hooke, 1975: Waves in the Atmosphere, Developments in the Atmospheric Sciences, Vol. II. Elsevier, 456 pp.

Haertel, P. T., and R. H. Johnson, 2000: The linear dynamics of squall line mesohighs and wake lows. $J$. Atmos. Sci., 57, 93-107, Crossref.

Handel, R. R., and P. Santos, 2005: Observations from the April 132004 wake low damaging wind event in south Florida. Electronic J. Operational Meteor., 6 (9), 1-9. [Available online at nwafiles.nwas.org/ej/pdf/2005EJ7.pdf.]

Johnson, R. H., 2001: Surface mesohighs and mesolows. Bull. Amer. Meteor. Soc., 82, 13-31, Crossref.

, and P. J. Hamilton, 1988: The relationship of surface pressure features to the precipitation and airflow structure of an intense midlatitude squall line. Mon. Wea. Rev., 116, 1444-1473, Crossref. , and D. L. Bartels, 1992: Circulations associated with a mature-to-decaying midlatitude mesoscale convective system. Part II: Upper-level features. Mon. Wea. Rev., 120, 1301-1321, Crossref.

Kapela, A. F., P. W. Leftwich, and R. Van Ess, 1995: Forecasting the impacts of strong wintertime post-cold front winds in the northern plains. Wea. Forecasting, 10, 229-244, Crossref.

Klimanek, M., T. Mikita, and J. Kolejka, 2008: Geoinformation analysis of factors affecting wind damage in the Šumava national park. J. Landscape Ecology, 1, 52-66, Crossref.

Knudson, M., 2012: Why do trees topple in a storm? Sci. American, Guest blog. [Available online at blogs.scientificamerican.com/guest-blog/why-do-treestopple-in-a-storm/.]

Koch, S. E., R. E. Golus, and P. B. Dorian, 1988: A mesoscale gravity wave event observed during CCOPE. Part II: Interactions between mesoscale convective systems and the antecedent waves. Mon. Wea. Rev., 116, 2545-2569, Crossref.

Lalas, D. P., and F. Einaudi, 1976: On the characteristics of gravity waves generated by atmospheric shear layers. $J$.
Atmos. Sci., 33, 1248-1259, Crossref.

Lighthill, J., 1978: Waves in Fluids. CahParidge University Press, 504 pp.

Lindzen, R. S., and K.-K. Tung, 1976: Banded convective activity and ducted gravity waves. Mon. Wea. Rev., 104, 1602-1617, Crossref.

Mitchell, S. J., 2013: Wind as a natural disturbance agent in forests: A synthesis. Forestry, 86, 147-157, Crossref.

NCEI, 2009: Storm events database. [Available online at www.ncdc.noaa.gov/stormevents/.]

NWS, 2008: Gradient winds - January 29th and 30th, 2008. [Available online at www.weather.gov/bmx/ event_01292008.]

Rochette, S. M., and P. S. Market, 2006: A primer on the ageostrophic wind. Natl. Wea. Dig., 30, 17-28. [Available online at nwafiles.nwas.org/digest/papers/ 2006/Vol30No1/Pg17-Rochette.pdf.]

Ruppert, J. H., and L. F. Bosart, 2014: A case study of the interaction of a mesoscale gravity wave with a mesoscale convective system. Mon. Wea. Rev., 143, 1403-1429, Crossref.

Simpson, J. E., 1997: Gravity Currents in the Environment and the Laboratory. 2nd ed. CahParidge University Press, $244 \mathrm{pp}$.

Smull, B. F., and D. P. Jorgensen, 1990: Pressure and buoyancy perturbations near an intense wake low in a midlatitude mesoscale convective system. Preprints, Fourth Conf. on Mesoscale Processes, Boulder, CO, Amer. Meteor. Soc., 214-215.

and C. E. Hane, 1991: Comparison of retrieved pressure and buoyancy perturbations with in situ observations of an intense wake low in a midlatitude mesoscale convective system. Preprints, 25th Int. Conf. on Radar Meteorology, Paris, France, Amer. Meteor. Soc., 135-138.

Stobie, J. G., F. Einaudi, and L. W. Uccellini, 1983: A case study of gravity waves-convective storms interaction: 9 May 1979. J. Atmos. Sci., 40, 2804-2830, Crossref.

Stumpf, G. J., R. H. Johnson, and B. F. Smull, 1991: The wake low in a midlatitude mesoscale convective system having complex convective organization. Mon. Wea. Rev., 119, 134-158, Crossref.

Tepper, M., 1951: On the desiccation of a cloud bank by a propagating pressure wave. Mon. Wea. Rev., 79, 61-70, Crossref.

Uccellini, L. W., 1975: A case study of apparent gravity wave initiation of severe convective storms. Mon. Wea. Rev., 103, 497-513, Crossref.

, and S. E. Koch, 1987: The synoptic setting and possible energy sources for mesoscale wave disturbances. Mon. Wea. Rev., 115, 721-729, Crossref.

Zhang, D.-L., and K. Gao, 1989: Numerical simulation of an intense squall line during 10-11 June 1985 PRESTORM. Part II: Rear inflow, surface pressure perturbations and stratiform precipitation. Mon. Wea. Rev., 117, 2067-2094, Crossref. 